\title{
Afecto y cuidado: pilar de la política social neoliberal
}

\author{
Carolina Rojas Lasch \\ Universidad Alberto Hurtado, Santiago, Chile. \\ Email: carojas@uahurtado.cl
}

\begin{abstract}
Resumen: Este artículo parte de la premisa de que en Chile ha habido un reposicionamiento político y moral de lo social que ha significado el presunto fin de la ola neoliberal de los 80 y 90 y una reestructuración de un Nuevo Estado Social. Sin embargo, sostengo que a través de una política que discursivamente se orienta proteger a los individuos y de una práctica de intervención que moviliza afecto y se orienta a cuidar, se instalan tecnologías de subjetivación y de gobierno que se articulan y refuerzan con la racionalidad neoliberal. Basado en dos estudios etnográficos, uno sobre las relaciones entre interventores y beneficiarios de la política de protección social y otro sobre las relaciones socio-culturales al interior de la escuela, mostraré cómo la política social contemporánea produce una nueva relación entre ciudadanos y Estado.
\end{abstract} ción social

Palabras Claves: Política social, neoliberalismo, afecto, cuidado, interven-

\section{Affection and care: pillar of the neoliberal social policy?}

\begin{abstract}
This article starts from the premise that, in Chile, there has been a political and moral repositioning of social matters that has meant the alleged end of the neoliberal wave of the 80s and 90s and a restructuring of a New Social State. Nevertheless, I argue that technologies of subjectivation and government are installed through policies oriented towards protecting individuals and through practices of affection and care. Such policies and practices articulate and reinforce neoliberal rationalities. Based on two ethnographic studies - one on the relations between enforcers and beneficiaries of social protection policies and the other about sociocultural relationships in schools - I will show how contemporary social policy produces a new relationship between citizens and the State.
\end{abstract}

Keywords: Social policy, neoliberalism, affection, care, social intervention

\section{Afeto e cuidado: pilar da política social neoliberal}

Resumo: Este artigo parte da premissa de que no Chile vem ocorrendo um reposicionamento político e moral do social, o que vem significando o suposto fim da onda neoliberal dos anos 80 e 90 e uma reestruturação de um Novo Estado Social. Contudo, sustento que através de uma política que discursivamente se orienta a proteger os indivíduos e de uma prática de intervenção que mobiliza afeto e se orienta a cuidar, instalam-se tecnologias de subjetivação e de governo que articulam e reforçam a racionalidade neoliberal. Com base em dois estudos etnográficos, um sobre as relações entre interventores e beneficiários da política de proteção social e outro sobre as relações socioculturais no interior das escolas, mostro como a polí- 
tica social contemporânea produz uma nova relação entre cidadãos e Estado.

Palavras-chave: Política social - neoliberalismo - afeto - cuidado intervenção social

\section{Introducción}

El 04 de diciembre del año 1972, en Nueva York, el Presidente Salvador Allende (primer presidente socialista de Chile y representante de la Unidad Popular-UP), tuvo la ocasión de hablarle a la Asamblea General de la ONU. A través de un discurso que ha quedado en las páginas de la historia nacional pero también mundial, Allende presentó al mundo la experiencia chilena de construcción de un proyecto de socialismo democrático. Con las palabras: "Vengo de Chile, un país pequeño...”, Allende introdujo un discurso que fue fuertemente aclamado por los representantes de la Asamblea. Sus palabras fueron de denuncia y proclamación de un proyecto de autonomía frente a la influencia económica y política de los poderes internacionales. Chile fue presentado como un ejemplo, la posibilidad cierta, de una democracia y de un gobierno de los trabajadores a partir de lo cual la redistribución económica y la justicia social fueron definidos por el presidente como los objetivos únicos y fundamentales del gobierno del pueblo.

"El pueblo de Chile ha conquistado el Gobierno tras una larga trayectoria de generosos sacrificios, y se encuentra plenamente entregado a la tarea de instaurar la democracia económica, para que la actividad productiva responda a necesidades y expectativas sociales y no a intereses de lucro personal. De modo programado y coherente, la vieja estructura apoyada en la explotación de los trabajadores y en el dominio por una minoría de los principales medios de producción, está siendo superada. En su reemplazo surge una nueva estructura, dirigida por los trabajadores, que puesta al servicio de los intereses de la mayoría, está sentando las bases de un crecimiento que implica desarrollo auténtico, que involucra a todos los habitantes y no margina a vastos sectores de conciudadanos a la miseria y la relegación social. Los trabajadores están desplazando a los sectores privilegiados del poder político y económico, tanto en los centros de labor como en las comunas y en el Estado. Este es el contenido revolucionario del proceso que está viviendo mi país, de superación del sistema capitalista, para dar apertura al socialismo” ”.(Discurso del presidente de Chile, Salvador Allende, durante la reunión de la Asamblea General de Naciones Unidas, 4 de diciembre de 1972).

Sólo nueve meses después de que el Presidente Allende se planteara así hacia al mundo desde la palestra de la ONU, Chile se sumergió por diecisiete años, en una dictadura militar que arrasó con el proyecto de la Unidad Popular y devastó los cimientos de Estado Social que a lo largo de todo el siglo XX el país había conseguido levantar. En su reemplazo, el 
gobierno dictatorial de Augusto Pinochet implementó a partir de los años ochenta políticas sociales neoliberales, a partir de las cuales lo social adquirió un lugar residual dentro de la política pública, expresándose en una reducción al mínimo del gasto público y de la acción en esta materia.

Treinta cinco años después del discurso de Allende, una escena similar sirve como referencia para analizar las transformaciones socio históricas que ha tenido la manera de distribuir, producir y asignar valor a lo social en la región. El 22 de Septiembre del año 2009, también en Nueva York, la presidenta Michelle Bachelet fue la expositora principal de la reunión de la Organización de Estados Americanos (OEA) vinculada a la Cumbre de las Américas ${ }^{1}$, en la que se hizo el lanzamiento de la Red Interamericana de Protección Social (RIPSO).Esta iniciativa había sido propuesta a comienzos del mismo año, durante la V Cumbre de las Américas ${ }^{2}$ y su propósito era crear una comunidad dirigida a identificar e intercambiar de manera permanente experiencias de políticas y programas sociales entre los países de la región. En la ocasión la presidenta Bachelet sostuvo:

"Una vez en el gobierno, nosotros hemos hecho también de la protección social el principal tema de la agenda; y de la construcción en Chile de un sistema de protección social justo, moderno y efectivo, su principal tarea en la perspectiva del establecimiento de un Estado social y democrático de derecho a la altura de lo que el esfuerzo de todos está haciendo posible” (Discurso de la presidenta de Chile, Michelle Bachelet, reunión OEA, 22 de septiembre 2009).

Tal como se observa, las palabras de la presidenta se dirigen a exponer públicamente a Chile como ejemplo, en un contexto en que el mundo entero se encontraba sumido en el punto más álgido de la crisis bancaria y financiera iniciada el 2008. Tal situación se sostenía en el hecho de que el país mostraba tener una economía sólida. Pero más importante aún para los propósitos de esta instancia, fue que desde comienzos del nuevo siglo los gobiernos socialistas de la región venían proclamando la superación de la ola neoliberal de los '80 mediante un interés por diseñar políticas dirigidas a revitalizar la acción del Estado en material de lo social. En este contexto, la experiencia chilena fue presentada como un modelo que debía ser replicado con urgencia en otros países de la región, en particular en aquellos que ya estaban sufriendo o se anticipaban a sufrir las consecuencias sociales de la crisis.

Evidentemente se trata de un momento simbólicamente fuerte. En primer lugar porque el abordaje de esta dimensión del quehacer del Estado no puede dejar de relacionarse con lo que representa en términos políticos y de género la figura de Michelle Bachelet: socialista y primera presidenta mujer de Chile. Y en segundo lugar, porque que este evento tiene un fuerte contenido re-fundacional, en cuanto la presidenta en su discurso marca un quiebre con el pasado. Sus palabras indicaron lo siguiente:

"Nos sigue pesando la todavía débil asignación de prioridades a los asuntos sociales, heredada de la pasada hegemonía neoliberal con 
su creencia en el mercado como panacea y un cierto desprecio por la acción del Estado” (Discurso de la presidenta de Chile, Michelle Bachelet, reunión OEA, 22 de septiembre 2009).

Con esta frase, la presidenta inserta este momento de celebración de la experiencia chilena en un continuo histórico. Durante toda la década de los '90, los gobiernos de la transición a la democracia habían realizado esfuerzos por dejar atrás la política social de la dictadura y plantearse como promotores de otro modelo social, sin embargo, hasta la década del 2000 esto no había sido posible. En aquel entonces, sin embargo, se observa que tanto la prensa como los analistas de la política chilena y mundial, identifican un retorno de lo social y asocian estas transformaciones en las políticas sociales latinoamericanas con una “izquierdización” de los gobiernos (Molyneux, 2007; Dabène, O., 2012; Luna y Filgueira, 2009). Es decir, la recuperación de lo social en el lenguaje político y en la acción del Estado del nuevo siglo se asoció con la superación de la ola neoliberal de los años '80 y ' 90 , la cual incluso fue nombrada como el inicio de un modelo postneoliberal (Vargas, 2007; Stoessel, 2014).

Sin embargo, el argumento que me interesa desarrollar en este texto, es que aunque los gobiernos de izquierda de la década del 2000 se declaran como modelos contrapuestos al neoliberalismo, lo que instauran son transformaciones en las formas de gobierno que no solo se articulan si no que ante todo refuerzan una racionalidad neoliberal ${ }^{3}$. La fundamentación de esta idea conduce de manera evidente a señalar que la política social que se promueve a partir del nuevo siglo camina en paralelo con las definiciones del modelo económico. Portan promesas redistributivas pero en su fondo no se proponen poner en cuestión el modelo económico. En este sentido, el argumento sería que el retorno a lo social no hace más que legitimar un status quo económico. No se toca ni se compite con el mercado, si no que se complementa para reforzarlo. Otra veta de análisis, que es la que sugiero seguir, entiende que la imbricación entre neoliberalismo y el fortalecimiento del Estado y de su rol público en materia de lo social se da a través de dimensiones menos evidentes y más difusas, más banales, en tanto operan como mecanismos de gobierno de los procesos de subjetivación y de construcción de una moral acerca de lo social y de los sujetos de lo social.En este sentido la transformación del rol social de los Estados refiere en términos más generales a la producción y consolidación de una nueva sensibilidad y forma de comprensión de las desigualdades. Sostener este argumento implica asumir que "las políticas sociales tienen, en la era neoliberal, la función de recrear un marco socializante a menor costo - sin creación de derechos universales y sí una función redistributiva a priori - con el fin de incitar tanto a hombres como mujeres a cumplir su función social respectiva” (Destremau y Georges, 2017. p.19). En este sentido, el neoliberalismo no corresponde sólo a un sistema económico o a una forma específica de Estado con más o menos de social, sino que a una forma de gobierno a partir de la cual se producen subjetividades y un tipo de ciudadanos neoliberalizados (Foucault, 2004; Rose, 1996; Rojas, 2015).Con esto último me refiero a que su integración o la consecución del bienestar se interioriza como una res- 
ponsabilidad, no pública, si no que privada: familiar e individual. En otras palabras, el rol prioritario que asume el Estado en materia de lo social, se orienta, tal como mostraré a continuación, a enseñar a cuidar a otros. Pero el cuidado, que pasa a ser concebido como el pilar central del bienestar, es fundamentalmente de responsabilidad de los individuos. Y sobre esto quiero mostrar a continuación que el estudio de la experiencia chilena resulta ser un buen ejemplo.

Para profundizar empíricamente en este argumento, analizaré en las páginas que siguen dos ámbitos que han sido estratégicos en la política social del nuevo siglo: la asistencia a los pobres extremos y las prácticas pedagógicas de atención a la vulnerabilidad. Para esto haré el ejercicio de articular dos terrenos etnográficos a través de los cuales me ha sido posible conocer y comprender las experiencias de dos figuras claves de la acción sobre lo social y de las relaciones que éstos establecen con sus públicos: las y los asistentes sociales y las y los docentes. A través del estudio de las prácticas de intervención asistencial realizadas al alero de la política de Protección Social Chile Solidario ${ }^{4}$ y de las prácticas docentes en establecimientos escolares identificados como vulnerables, en las páginas que siguen me propongo mostrar cómo esta forma contemporánea de gobierno neoliberal se sostiene en la producción de compromisos intersubjetivos que son profundamente morales. En específico el quehacer de estos agentes de lo social, en quienes se encarnan las políticas del Estado, se trata de una acción que se sostiene, no sin conflictos, en dos pilares: el vínculo afectivo y el cuidado.

\section{Intervenir desde lo íntimo}

Entre el 2008 y 2012 realicé una etnografía de las formas contemporáneas de intervención social dirigidas a la población vulnerable que se enmarcan dentro del Sistema de Protección Social Chile Solidario ${ }^{5}$ (que es en la que se inspiró el modelo de política social que la Presidenta Bachelet presentó en la reunión en la OEA anteriormente mencionada). El terreno comprendió la observación al trabajo que realizan los y las asistentes sociales con las familias durante las visitas domiciliarias. Estas políticas rompen radicalmente con la imagen distante de la ventanilla municipal de la asistencia, el guichety se vuelcan hacia un trabajo personalizado. Ir hacia los beneficiarios, se impone a través de esta política como un nuevo esquema organizador de la acción pública contemporánea (Cefaï y Gardella, 2011, p. 51).

Dentro de este marco, las visitas domiciliarias y la acción que ocurre en la intimidad de los hogares de los y las beneficiarias, es uno de los dispositivos centrales de la nueva lógica de intervención social (Rojas, 2014). Pero resulta interesante remarcar que esto se despliega en paralelo con el desarrollo de un modo de gestión pública que se declara cada vez más objetiva y despersonalizada, orientada a procesos de mayor racionalización, impregnada de tecnicidad y con formatos de gestión inspiradas en los enfoques del management(Rojas, 2010, 2015; Chauvière, 2007). 
Así se observa la convivencia de una doble lógica en el quehacer del Estado, que es aparentemente paradojal y novedosa dentro de los modos de hacer política pública. En este sentido, la práctica de visita y el trabajo próximo, que sabemos ha sido históricamente utilizada por la asistencia social (Illanes, 2006) hoy se imbrica con mecanismos de modernización del Estado, que promueven mecanismos sistemáticos, estandarizados y centrados en el control de la gestión. Dicho en otros términos si antiguamente la acción asistencial se caracterizaba por intervenciones moralizadoras y disciplinarizadoras, hoy funcionan de manera más difusa y confusa, articulando una práctica de orden y cuidado (care), de coerción y empatía (Fassin, 2011).

Lo social entonces, encuentra un espacio legítimo por sobre (sin cuestionar) lo económico neoliberal porque sigue el mismo lenguaje de la burocracia -racionalización y neutralidad-, mediante la implementación de sofisticados mecanismos de seguimiento y evaluación que terminaron siendo más importante que la "verdadera" superación de la pobreza de las familias ${ }^{6}$. Sugiero, tal como mostraré a continuación, que tal relación de cercanía y racionalización de la acción se justifica porque resulta ser altamente eficiente. Entre otras cosas, esto debido a que el trabajo afectivo (por ejemplo de trabajadoras sociales o como mostraré en lo que sigue de profesoras) de alguna forma subsidia la capacidad del Estado de mantener la asistencia mediante un modelo precario y de condicionalidad. Al final las profesionales asumen y se hacen cargo del desborde afectivo/emocional que no logra ser contenido por la supuesta neutralidad o tecnicidad que sostiene o fundamenta este modelo de intervención.

A continuación presento un extracto de mis notas de terreno en la que relato mis observaciones durante el acompañamiento al trabajo de visita domiciliaria que realiza una asistente social y que ayudan a figurar la idea anteriormente mencionada:

"Son las 10.30 de la mañana luego de una fuerte noche de lluvia. Acompaño a Pilar en sus visitas domiciliarias. Llegamos a un sitio cerrado por muros de cemento en el cual hay un portón semi abierto. Pilar ya conoce el lugar y decide entrar. Es un terreno de piso de tierra en el que hay tres mediaguas, nosotros vamos a la que está más al fondo. Hay un gran barrial y pozas, pero hay dispuesto unos tablones por los que caminamos haciendo equilibrio hasta llegar a la casa del fondo. Pilar llama con un grito y a los minutos aparece una señora en pijama. La señora nos hace pasar diciendo: 'qué vergüenza... qué bueno que vienen, tengo hartas cosas que contarles'. Entramos a la primera pieza que está adecuada como cocina comedor, pero nos pide pasar a la segunda que está ocupada como dormitorio. Mientras entramos la señora pide disculpas. Hay una cama de dos plaza pegada a otra de una plaza. Ambas están ubicadas en el centro de la habitación, es decir desapegadas de los muros por los cuales se nota que cayó agua de lluvia. El suelo está con papeles de diarios mojados. El olor a humedad, encierro, transpiración y comida es muy desagradable. Adentro de las camas hay un niño y una guagua que 
llora. 'Estábamos durmiendo... ¿está muy hediondo? - pregunta la señora- . Anoche nos amanecimos porque nos llovimos'. Nos invita a sentarnos 'donde puedan', mientras ella vuelve a posarse sobre la cama, toma a la bebé en brazos y comienza a darle pecho (Notas de campo, 2009).

La interacción de los funcionarios de la asistencia con las familias, se da en condiciones que lejos de ser de orden exclusivamente administrativa y profesional son domésticas e íntimas. El olor de las casas, tener que sentarse a los pies de la cama mientras alguno de los miembros de la familia en particular las mujeres, están acostadas, tener que solicitar el baño de las familias, aceptar almorzar con las familias o tomar un té o un café, llegar a la casa en invierno cuando se están lloviendo o no han podido ventilar, etc. son algunas de las múltiples situaciones a que se ven enfrentado en el día a día estos agentes de lo social. Tal como lo muestra Daniel Cefaï y EdouardGardella (2011) en su etnografía sobre el Servicio de Ayuda Médica de Urgencia - SAMU en Francia, el olfato es uno de los sentidos que está en el corazón de la lucha contra la exclusión. Citando a Georg Simmel, los autores afirman que la cuestión social no es solo una cuestión de ética, sino que también una cuestión de nariz.

En la práctica de asistencia el contacto con lo íntimo afecta en al menos tres direcciones. Primero, provoca emociones fuertes o violentas (conmoción, pena, asco, empatía, etc) llegando a veces al límite de lo soportable (Cefaï y Gardella, 2011). Producto de esto se fija una distancia inicial entre los agentes de la asistencia y las familias. Esta reacción de alejamiento es evidentemente física, pero también refuerza una distancia moral (Marché-Paillé, 2010), ya que pone de manifiesto una situación (doméstica, económica, cultural) socialmente indeseable y/o inadecuada. Segundo, y en relación a lo recién dicho, la proximidad es poderosamente estratégica y eficaz. Cuando los funcionarios de la asistencia se sobreponen a la afectación producida por el contacto con lo precario de las vidas de las familias asistidas (en el caso del extracto, el desagrado), avanzan eficazmente en la construcción de la confianza, del vínculo y de la proximidad que de cierto modo la política social contemporánea de protección social incita y promueve. En este sentido el desagrado y en general el cuerpo a cuerpo en la intimidad de los profesionales con las familias, tiene también un tremenda fuerza política. Y tercero, la afectación asociada a la proximidad asistencial pone al límite la ética y la vocación de los y las interventoras.Son situaciones que los ponen profesional y personalmente a prueba y a partir de los cuales hacen de su quehacer una práctica activa sobre la cual deben tomar permanentemente decisiones (Memmi, Raveneau, y Taïeb, 2011).

En este sentido, entrar en lo íntimo, acortar la distancia, alcanzar la presencia social (Bessin, 2014), afectarse, resulta ser también estratégico e incluso profesionalizante.En otras palabras, aceptar compartir la intimidad es invertir en la confianza intersubjetiva esperada por este nuevo modo de hacer de la política social. En este sentido, es una habilidad práctica de justicia perceptiva y apropiación moral (Cefaï y Gardella, 2011, p.163) 


\section{Educar a estudiantes "difíciles"}

Entre los años 2013 y 2015, en el marco de una investigación colecti$\mathrm{va}^{7}$, llevamos a cabo un trabajo etnográfico de la vida cotidiana (lo ordinario, el día a día) de espacios escolares de la Región Metropolitana. Este trabajo tuvo como antecedente el hecho de que los cambios producidos en las últimas décadas a nivel de las sensibilidades de lo social habrían relevado en los espacios escolares la existencia de nuevos problemas, tales como: la segregación, el bullying, el abuso, la discriminación, entre otros. Estas cuestiones, que hace algunas décadas no eran ni nombradas ni cuestionadas, llegan a figurarse en el espacio público y en la agenda política como situaciones intolerables (Bourdelais, P. y Fassin, 2005).

El extracto de las notas de campo que presento a continuación corresponde a observaciones realizadas en una escuela municipal, mixta, pequeña (un curso por nivel),en la que hay un alto índice de deserción de estudiantes y cuyos resultados, según las pruebas estandarizadas nacionales, son muy bajos.Tiene un alto porcentaje (alrededor de un 40\%) de población estudiantil migrante y aproximadamente el $80 \%$ de niños y niñas ha sido diagnosticado (formal o informalmente) con necesidades educativas especiales (NEE) y/o en situación de vulnerabilidad. Producto de esto, la escuela cuenta un número importante de alumnos (cercano al 70\%) que participan del Programa de Integración Escolar - PIE $^{8}$ o ha sido identificado por la política como alumno prioritario (en función de lo cual las escuelas reciben financiamiento específico). Según el proyecto educativo, y tal como lo señala Verónica que es la profesora a quien me refiero a continuación, la escuela se reconoce a sí misma como una escuela "puertas abiertas".

Verónica se incorporó hace poco a la escuela como profesional de apoyo contratada con recursos de la Ley $\mathrm{SEP}^{9}$. Su trabajo consiste en hacer reforzamiento a los niños prioritarios y que no están en el Programa de Integración - PIE pero que según dice:

"Sí, les cuesta. No tienen ningún diagnóstico como tal, pero presentan dificultades. Esta es una escuela inclusiva, y obviamente al ser inclusiva, hay diversidad de niños, pero la diversidad se manifiesta principalmente en la parte emocional, cognitiva y siquiátrica, que es lo más difícil. Yo siento que necesitamos más especialistas o más capacitaciones para nosotros para poder manejar el tema de inclusividad porque nosotras somos profesoras básicas las que estamos trabajando. Si bien tenemos nociones de lo que sucede y de los tipos de diagnóstico que se pueden presentar, pero no somos especialistas” (Notas etnográficas, 2013).

A continuación de esta afirmación, la profesora le dice a la etnógrafa:

"los niños están muy carentes de afecto, sus emociones están a flor de piel, entonces cualquier cosa que los irrite, ellos explotan solamente. Yo creo que el tema pasa por la familia”. (Notas etnográficas, 2013). 
Verónica comenta que ha hablado con pocos apoderados, pero que ella cree que los niños se sienten un poco abandonados y que a quienes tienen para manifestarlo es a los y las profesoras que son quienes están diariamente con ellos.Su relato continúa:

“Es como: mírenme, estoy acá, respiro, necesito atención, y la única forma que ellos saben o han aprendido es estando en la calle, o quizás dónde, es de esa forma. Porque no hay día que uno aquí no separe a los niños peleando. No hay día que un niño aquí no te agreda o te trate de lo peor"

La etnógrafa le pregunta cómo ha resuelto esas situaciones de agresión. Me cuenta que lo más grave que le ocurrió fue en el curso de primero básico con Benjamín:

“Él tiene 10 años y va en primero. Es como de mi porte, si yo soy baja. Y se quería escapar de la sala. Yo lo contuve, conversé con él trate de...porque yo siento que al Benjamín le falta que lo agarren, lo aprieten, lo contengan, le den besos, que lo quieran...entonces, sí he logrado muchas cosas con él. De hecho todos los niños me decían: ¿tía, pero no está enojada con el Benjamín? - No, no estoy enojada con el Benjamín porque tuvo una reacción que no fue buena, pero le podría haber pasado a cualquiera. Yo traté de detenerlo y él tomó distancia y empezó a correr y me tiró lejos contra puerta y yo... ese día yo no quería decir nada porque lo podían suspender y yo no quería eso, pero ya era demasiado el dolor y me vio la tía Lily, la jefa de UTP y ahí me preguntó qué había sucedido, le contesté y ahí llamaron a la mamá y ahí no supe más de Benjamín como en 3 días porque lo habían suspendido. Que era lo que yo no quería que pasara. (...) Entonces ¿qué pasa? que uno sigue aceptando que el niño no trabaje, que te llene de garabatos todo el día, que haga lo que él quiere, porque eso es lo que pasa, porque él hace lo que él quiere acá en la escuela por no hacerle más daño de lo que ya tiene. Porque no hay compromiso de él, no hay compromiso del apoderado. Entonces si no hay compromiso de su familia ¿̇a quién más les podemos pedir un apoyo? Entonces como no podemos darle un apoyo a nadie más, se lo damos nosotros. Y en una lucha constante, tratando todos los días de lograr algo por él. (...) Por un lado están los niños que de una u otra forma, a pesar de uno sabe que no tiene que involucrarse emocionalmente, igual uno se involucra, y por otro lado están los jefes que están todo el día ahí, y los niños (mueve el cuerpo como si la tironean de un lado y el otro) Noo.. ¿¿qué hago? por favor, necesitamos un flotador y no se da” (Notas etnográficas, 2013).

La potencia del relato de esta profesora está en el hecho de que en torno a la idea de protección social y de inclusión, se articulan dos procesos propios de esta nueva sensibilidad neoliberal sobre lo social. Por una parte, aun cuando se recurre a diagnósticos médicos, psicológicos o sociales para justificar las conductas disruptivas de algunos (en este caso de la 
mayoría) de los y las estudiantes, en la dinámica cotidiana de la escuela la solución pareciera estar en el plano de los afectos. Es decir, en la disposición y afectación hacia el otro así como en la comprensión biográfica, emocional, familiar e íntima de su historia.

En este sentido, la acción pedagógica, al igual que la acción asistencial, pareciera remitir más que a conocimientos o criterios profesionales, a disposiciones afectivas e intersubjetivas. La consecuencia de esto, es la angustia y agobio que esto provoca en los profesionales ya que su paciencia, bondad o corazón no da para todos.

\section{El vínculo: compromiso moral y afectivo}

Los terrenos etnográficos que he presentado dan cuenta o permiten de manera complementaria describir cómo opera y en qué consiste la nueva sensibilidad y racionalidad sobre las desigualdades y sobre la gestión de lo social en Chile.Ambas escenas etnográficas revelan cómo la acción de la política social contemporánea se sostiene en una afectación interpersonal frente al estado de necesidad identificada en los beneficiarios, es decir una individualización de una situación de vulnerabilidad. En el caso de Pilar, la asistente social, saber sobreponerse al desagrado asociado al contacto de lo íntimo de lo doméstico, es una manera de probar, a nombre o en nombre del Estado, un interés genuino por la realidad de cada familia. Así mismo, en el caso de Verónica, la profesora, ocultar la agresión de Benjamín resulta ser indirectamente un modo hacer bien su trabajo, en la medida que su rol, y a través de ella la acción del Estado, es la protección.En concreto, la idea de vínculo y el trabajo personalizado con los usuarios/beneficiarios de la política social (clasificados y seleccionados en función de la identificación de sus grados de vulnerabilidad) se instala, tal como indiqué en el contexto de la política social, en particular asistencial y educativa, como el elemento clave de la práctica cotidiana de trabajadores/as sociales y de profesores/ as (Rojas, 2014).

Podemos decir entonces, que el quehacer sobre lo social ha sido reinscrito desde el corazón de los sujetos (Fassin et al., 2013), conjugando afectos e identidades e instalando una valoración especial a aquella acción social de alta proximidad intersubjetiva (Cefaï y Gardella, 2011). Siendo así, es una intervención social que compromete un sentimiento de compasión asociado a situaciones de sufrimiento y reciprocidad. Esto se observa en la movilización de sentimientos y de un léxico moral tanto para acceder a ayudas o beneficios como para probar su situación y justificar el mérito a la ayuda.

Ahora bien, tal como mencioné anteriormente, este lugar que se le ha dado a la experiencia cariñosa y a lamovilización de los afectos en el quehacer del Estado, se conjuga con aspectos específicos de la gestión de las políticas de la vulnerabilidad. Por ejemplo, las políticas de asistencia que se crean a partir del nuevo siglo, se enmarcan dentro de un tipo de gestión 
asociado a lo que se ha entendido como transferencias condicionadas (Valencia Lomelí, 2008). Este tipo de acción se sostiene en la idea de que los beneficios de la política se obtiene mediante la demostración de un conjunto de acciones realizadas por las familias e incitadas por la intervención directa, las cuales se orientan a cumplir con mínimos definidos como claves para la inserción social (por ejemplo, certificados de asistencia a las escuelas por parte de los hijos, de atención médica, demostración de esfuerzo mediante la participación en capacitación y búsqueda de empleo, etc). Para esto, se diseñan y crean mecanismos institucionales e informáticos que permiten monitorear y atribuir veracidad a los logros de las familias, en función de las cuales es posible de manera despersonalizada atribuir beneficios (bonos). Para el caso de educación por ejemplo, el trabajo con los estudiantes vulnerables se establece como un modo de financiamiento de la educación pública. Mediante el diseño de instrumentos estandarizados para el diagnósticos y de identificación de la situación de vulnerabilidad de los sujetos, se define una población específica (número de estudiantes) en función de la cual se atribuyen recursos extras a las escuela (ejemplos de estos instrumentos son el Decreto 170, el IVE, el puntaje obtenido mediante la Ficha de Protección Social que luego deriva en el Registro Social de Hogares) (Infante et al. 2013; Peña, 2013). Entonces el trabajo intersubjetivo, afectivo convive y se fortalece con la solidificación de sistemas de gestión que buscan eficiencia en el gasto.Y esto ocurre de manera independiente a los logros efectivos que estas políticas puedan tener en términos de los principios que orientaron su creación, es decir al impacto esperado ${ }^{10}$. Osea, la sola eficiencia de estos dispositivos justifican su implementación.

De este modo, vemos cómo el vínculo y la relación intersubjetiva compromete y obliga, lo que en términos de esta nueva forma de hacer política social se articula con la idea de condicionalidad (Cecchini, y Madariaga, 2011), haciéndola entonces eficiente, lo cual es criterio central de una práctica neoliberal. De este modo, las políticas sociales se alejan de principios solidaristas (Castel, 1995) a partir de los cuales los problemas sociales son problemas de sociedad (Procacci, 1993) y se aproxima a principios liberales, desde los cuales lo social se restringe a situaciones específicas de ciudadanos particulares y se resuelven con la ayuda del Estado pero, en el ámbito de lo íntimo y de lo privado. De este modo, la política social contemporánea se caracteriza por movilizar e incitar el desarrollo de un trabajo relacional cuyo fin es ayudar a recuperar y reactivar la solidaridad bajo condiciones neoliberales y crear una forma de vida que parece no tan atomizada o aislada. Es un intento de construir relaciones sociales a través de actos de intensa comunión moral y cuidado. (Muehlebach, 2012).

\section{Un Estado que cuida a sus ciudadanos}

El enfoque que he utilizado para profundizar en este nivel intersubjetivo del quehacer del Estado es el que proviene de las teorías feministas en torno al estudio del care. Este es un concepto que tanto la filosofía como las ciencias sociales ha consensuado guardar su nomina- 
ción en inglés debido a las grandes dificultades de traducción. Pero a groso modo, refiere a aquellas formas de atención, disposición, solicitud dirigida hacia otro. En español la referenciamás literal sería pensar en la idea de "cuidado". Los orígenes de esta discusión se remontan a la década de los '80 cuando desde el espacio de la filosofía anglosajona, se sugiere que el carecorresponde a la vertiente femenina de la justicia (Gilligan, C. 1982). Esta idea, que en su momento fue insumo para el fortalecimiento de un feminismo estratégico, es rápidamente puesto en cuestión a propósito del esencialismo que supone tal idea. En este contexto, se desencadena un debate rico, dentro del cual es emblemático el trabajo de Joan Tronto con su libro Moral Boundaries : a PoliticalArgumentforanEthic of care, que fue publicado en el año 1993. En este trabajo la autora se propone desarrollar una teoría general del carepero sobre todo, propone el desarrollo de una teoría crítica que se orienta a denunciar y exhibir la marginación tanto de las prácticas como de las personas que lo realizan. Desde el escenario francés, que se suma tardíamente en la discusión, se observa desde hace algunas décadas, que este tema ha sido reabierto, permitiendo extender y complejizar aún más la discusión (Paperman\&Laugier, 2005; Brugère, 2008; Dorlin, 2005, Molinier P., 2010, 2013; Nicole-Drancourt, y Jany-Catrice, 2008; entre otros).

El gran valor de estas perspectivas críticas para el feminismo, refiere a que permite poner a la luz dimensiones invisibilizadas en lo que respecta a las prácticas y políticas de bienestar. Estas autoras, identificándolo como una herramienta analítica que da cuenta de un modo de hacer lo femenino, que en este caso puede asociarse al quehacer del Estado. Así entendido, la proximidad y el cuidado permite por una parte dejar en evidencia en términos descriptivos, cómo la política social actual instala y legitima la afectación (Ahmed, 2004a; 2004b) como un modo de hacer y producir la política social asistencial y educativa. Y por otra parte, ofrece analíticamente un campo de observación de dimensiones morales de las formas de acción pública, tales como la generosidad y la confianza. En particular me he interesado en aquellas perspectivas que conciben el carecomo un modo generizado de análisis político y moral de las desigualdades (Bessin, 2014). A partir de este enfoque, más que un objeto de estudio (asociado a las formas de cuidado directo, a las prácticas de atención a otros) el care puede ser visto como un modo de aproximación epistémico para analizar las dimensiones temporales, espaciales, morales y sociales del quehacer sobre lo social y así relevar los sentido políticos y morales de la acción pública contemporánea.

Estos debates contemporáneos en torno al care, han permitido desencializar el lugar del género en el análisis de estas disposiciones y actitudes y posicionarlo también desde perspectivas feministas de tipo performativas. Con esto me refiero a que ayudan a entender cómo las instituciones sociales, en este caso las políticas sociales, prefiguran, sostienen, refuerzan, enseñan, conducen prácticas generizadas. Así, desde esta concepción, se complejiza la idea inicial del care, que comprendía que las formas suaves o cariñosas de hacer lo social se deban a que son mayoritariamente mujeres quienes trabajan y se desempeñan en lo social o 
bien han sido las que han pensado y diseñado la política contemporánea.En otras palabras, estas perspectivas del care, permiten ir más allá de su comprensión en términos de una acción femenina (ya sea realizada directamente por mujeres o por un Estado que opera desde lógicas femenizadas) y abre analíticamente la posibilidad para comprender que estas formas de interdependencia, por ejemplo entre asistentes y asistidas, profesoras y estudiantes, tienen un sentido político. Con esto me refiero a quehacen circular, reproducir, sostener una lógica política acerca de lo femenino. Es decir, el care puede ser visto como un recurso relacional que política y moralmente estructura el modo de hacer la acción social neoliberal.

En concreto y a propósito de los casos estudiados, esto significa posicionar a los géneros en identidades fijas, en función de lo cual a la trabajadora social y a la profesora se le asigna el rol de acoger y atender a los beneficiarios de la política y de este modo ellas le enseñan performativamente a la mujer-madre a cuidar a los miembros de su familia. En este sentido como sostienen algunas autoras (Duggan, 2003; Brown, 2006; Puar, 2007), existiría una relación estrecha entre una racionalidad económica neoliberal y una racionalidad política y cultural neoconservadora.

Tal como lo propone Andrea Muehlebach (2012), el orden neoliberal contemporáneo no sólo produce sujetos racionales, utilitarios e instrumentalista, como en la versión clásica del liberalismo. Nuevas formas de neoliberalizacion producen simultáneamente un ser afectivo, en términos de ser compasivos empático, que se propone como el universo social y moral del neoliberalismo. La moral neoliberal, "se refiere a la creación de un nuevo sentido del sí mismo y del buen ciudadano. De interioridad y de acción, de sensibilidad y de agency (Muehlebach, 2012). Este tipo de atención a la moral neoliberal, en el sentido que le da la autora, nos permite observar cómo prácticas y fuerzas que se crean en oposición o críticas al neoliberalismo se pliegan a él en un orden único y participan ambivalentemente en su proceso.De este modo, nuevos tipos de vida colectiva pueden emerger desde y a pesar de nuevas formas de inequidad.

Esta nueva cultura de los sentimientos de cuidado y de proximidad abre una posibilidad para reinterpretar las características de la acción pública contemporánea. Esta práctica dirigida a cuidar, considero que puede ser identificada como un nuevo campo de acción del Estado, lo social asistencializado (Rojas, 2015). Este consiste en un modo de hacer acción pública, sistemática, burocratizada, racional, pero a su vez personalizada, próxima, directa, que se orienta a producir care. Es un modo de enseñar a cuidar: reposa sobre la construcción de un consentimiento de los destinatarios frente a medidas que emanan de instituciones que se preocupan de ellos, los atienden, los cuidan y les prestan atención, (Destremau y Georges, 2017, p.21). Es una manera de reestablecer la sociabilidad primaria, las confianzas, los afectos, la reciprocidad, pero lo hará paradojalmente a través de la institucionalización de mecanismos compensatorios y condicionados que delegan la responsabilidad de los logros en este caso sociales y/o educacionales en los propios sujetos. En otras palabras, consiste en estrategias 
dirigidas a instituir tanto en la acción pública, como en sus funcionarios y en sus usuarios, una actitud o disposición de ayuda, acompañamiento y apoyo. Instauran principios próximos a la caridad, a la voluntad de quien atiende o acompaña y al establecimiento de una relación paternalista; pero institucionalizándolos como la manera en que el Estado desarrolla mecanismos de seguridad y protección. Es decir, si bien lo social y en los casos que aquí abordé, la protección social y la educación, aparecen y se nombran como una cuestión de derecho, El Estado los trata y gestiona en términos de ayuda y cuidado interpersonal. Es en este sentido que se observa el relevamiento de un sentido de care público dirigido a producir, fabricar o incitar el desarrollo de un care privado (Destremau y Georges, 2017).

En síntesis, la relación entre cuidado y neoliberalismo nos conduce al debate en torno al bienestar, en donde, siguiendo el ya clásico modelo de Esping-Andersen,la familia, en desmedro del Estado o del Mercado, vuelve a adquirir una prioridad. $Y$ en particular, al pensar en familia, se entiende a la mujer a quien se le ha de enseñar a cumplir con su rol principal que es cuidar (Rojas, 2014).

\section{Una nueva relación entre el Estado y los ciudadanos}

$\mathrm{Al}$ inicio de los '90 en Chile, en el contexto de una "transición pactada” y de una “democracia de los consensos” (Bascuñán, et al, 2009), los miembros y representantes de los gobiernos postdictatoriales que al término de la dictadura habían sido críticos acérrimos del modelo neoliberal chileno, no pusieron en cuestión los fundamentos de la política económica y de la política social heredada. Los nuevos gobiernos de transición a la democracia,responsabilizaron a la dictadura de las altas tasas de pobreza y designaron al individuo pobre como una víctima de la violación a los derechos "sociales". De este modo, durante toda la década de los '90 la política social se orientó a compensar o restaurar política y moralmente a las víctimas del sistema económico (los grupos más pobres), a partir de lo que se concibió como una "deuda social” (Serrano, 1992). Tal como afirma Clara Han (2012) en su etnografía sobre las formas de vida de los pobres en Chile al inicio de los '90, la noción de deuda marca una nueva relación entre el Estado y la población pobre.

Pero a partir del nuevo siglo, y habiendo transcurrido una década de gobierno democráticos, la asociación de la política social con la existencia de una deuda del Estado dejaba de ser sostenible en términos políticos. Es entonces que los enjeux políticos y sociales asociados a la promesa y expectativas de un gobierno de centro izquierda crean condiciones para reposicionar las responsabilidades del Estado en materia de lo social. Pero al contrario de aquellos planteamientos que sostienen que las transformaciones ocurridas en las políticas sociales chilenas de comienzo del nuevo siglo rompen con la tendencia neoliberal y se orientan a construir un Nuevo Estado Social, en este texto he propuesto que lo que se ha producido es una transformación en la sensibilidad y tecnologías de acción sobre lo social, a 
partir de las cuales se instituyen nuevas formas de gobierno que actualizan y refuerzan la racionalidad neoliberal.

En coherencia con las reglas neoliberales ligadas a la razón gestionaria y el management liberal (Chauvière, 2007) hoy la política social es altamente modelizada en términos de mecanismos de regulación asociados al cálculo y rendimiento económico, tales como la racionalización, la evaluación, el individualismo y formas utilitarias de relación social (metodología estandarizada de intervención, de sistematización, monitoreo y diseño de tecnologías de gestión y evaluación). Sin embargo, esta lógica neoliberal de management social, se combina y finalmente se sostiene en una disposición afectiva y moral. Esta característica de la configuración contemporánea de la intervención social neoliberal Astier (2007) la ha denominado como "las nuevas reglas de lo social" y se caracterizan por un trabajo de tipo interpersonal tendiente a una autonomización familiar del bienestar y por tanto a una responsabilización privada para lo cual se hace necesario la activación, acompañamiento, etc.

En este contexto, siendo la política social expresión de una neoliberalización de lo social, económica y material, resulta ser precaria y restringida y al mismo tiempo altamente moral y subjetiva. Precaria en términos del presupuesto del cual dispone, en las condiciones en las que se implementa, en los beneficios que presta, en la realidad sobre la cual se quiere trabajar, etc. Moral y subjetiva ya que se sostiene en términos concretos en una relación específica y particular entre dos personas, asistidos y asistente, estudiantes y docentes en la que movilizan principalmente emociones y obligaciones mutuas. Así, las intervenciones que derivan de este modo de hacer lo social son la consecuencia de una afectación personal frente al estado de necesidad de un otro y que por tanto compromete y obliga.

Relevo este último aspecto, porque la labor de los agentes de la acción social (en este caso, profesionales del campo de la intervención y la educación) en cuanto representantes del Estado ha sido históricamente cuestionada por perspectivas críticas en términos de su rol de control social. Dicho de otro modo, el lugar de estos actores que encarnan al Estado en su vínculo con los individuos y ciudadanos, encarnan también de cierta manera procesos de dominación. Ahora bien, en el contexto de esta política de protección social neoliberal, los agentes de la acción social son demandados a generar también una acción que los resitúa en un lugar de alta proximidad estatutaria con los sujetos con quienes trabaja. Es decir, la proximidad y el trabajo intersubjetivo, también implica unanueva relación entre el Estado y los ciudadanos. Tratándose de una política que se acota al campo de lo intersubjetivo descolectivizando y despolitizando la responsabilidad de la existencia de las desigualdades, conduce a que a los agentes del Estado y de la política social deban restringir su acción a un ofrecimiento de sí mismos en tanto sujetos. De este modo, se observa una homologación de posiciones entre el usuario y los funcionarios (Spire, 2008, p. 15). La autoridad de estos funcionarios y de subordinación de los asistidos se desdibuja ya que de cierto modo también les toca sobrevivir como sujetos 
“a” y “en” la experiencia de intervención inciertay precarizada.

Si la precariedad hace que los agentes de lo social operen dentro del marco de "lo posible", los sujetos que participan de la relación de poder asociada a la asistencia se encuentran en permanentemente producción de su posición frente al otro. La idea de hacer lo "posible” permite crear expectativas afectivas en los individuos/ciudadanos y agentes de la intervención /Estado y condiciona la acción de unos y otros (a nivel de conductas, disposiciones, tareas) al tiempo que permite justificar las demanda y la distribución debeneficios precarios.

De este modo, sostengo que el Estado se hace activo en términos sociales incitando y produciendo un ciudadano, ciudadana, responsable de cuidar. Y esto lo hace desde la experiencia misma de una intervención afectuosa. En este sentido, lo neoliberalizado de los ciudadanos, no se condice de manera directa con una disposición a la competencia con otros, ni a nivel del mercado. Por el contario, estando fuera del mismo y sin que sea el propósito de estas políticas que en términos estructurales se inserten en él, les enseñan mediante su inserción en el campo de la institucionalidad social, a que son ellos quienes deben proveer su bienestar y que por tanto no conseguirlo es su responsabilidad. Y en esto la familia, en particular la mujer, es central. De este modo, la lógica de gobierno actúa en el control y sostenibilidad de un orden neoliberal.

\section{Reflexiones finales}

En general, los análisis de políticas neoliberales latinoamericanas de los años '80, se concentraron en el hecho de que habían provocado una delegación de las responsabilidades sociales del Estado a instituciones privadas, es decir una privatización. Sin embargo, en la década del 2000, el modelo de gestión de lo social que se instaura refuerza y construye más Estado para lo social. Se trata de una política social regulada, controlada, financiada e implementada por el Estado. En base a esto es que ha sido posible argüir que se habría dado por superada la ola neoliberal, pero en este artículo he querido complejizar este supuesto. En el modelo estatal que se implanta a partir del nuevo siglo, la cuestión del neoliberalismo se juega fuertemente en que la responsabilidad de la gestión de la vulnerabilidad se transfiere a los individuos.

A través de este proceso, sostengo que se ponen en juego formas específicas de vinculación entre el Estado y los individuos de los que debe hacerse cargo.El principio de responsabilidad define lo deseable y lo indeseable. En lo que respecta al Estado, lo deseable es generar un vínculo cariñoso de modo que los ciudadanos se “sientan" vistos y lo indeseable es la ineficiencia de la gestión pública. Y en lo que concierne a los individuos, lo deseable es que en reconocimiento a que han sido vistos y queridos por el Estado “se dejen intervenir”, es decir una especie de dependencia emocional y lo indeseable es su dependencia material. 
En síntesis, una de las características de este nuevo modo de hacer lo social por parte del Estado neoliberal es que actúa desde el corazón de los sujetos, conjugando afectos e vínculos intersubjetivos. La idea de proximidad y el trabajo personalizado se instala en el contexto de la política asistencial y educativa como el elemento clave, como un indicador de éxito y como recurso diferenciador de las políticas precedentes. Lo que se espera de estos agentes es que sean "buenos", "tolerantes", "esforzados", "pacientes", "cariñosos", ya que a través de estas disposiciones se puede llegar a incidir en los sujetos y familias identificadas como "vulnerables". En este sentido, el abordaje de lo social neoliberalizado, implica un descentramiento desde aquello que en sus orígenes se entendió como una “cuestión social”,hacia un asunto de individuos.

\section{Agradecimientos}

Este artículo fue elaborado en el marco del Proyecto FONDECYT Regular 1160732 "El problema de nombrar: currículum, conocimiento y la construcción de la normalidad y la diferencias en escuelas chilenas" que cuenta con el financiamiento de CONICYT. 


\section{Notas}

${ }^{1}$ Ésta actividad coincidía con el $64^{\circ}$ Período de Sesiones de la Asamblea General de la ONU.

${ }^{2}$ Celebrada en "Puerto España” en capital de Trinidad y Tobago entre los días 17 y 19 de abril de 2009. El tema que convocó a esta cumbre fue "Asegurar el futuro de nuestros ciudadanos mediante la promoción de la prosperidad humana, la seguridad energética y la sostenibilidad ambiental”.

${ }^{3}$ Esta idea adquiere aún más fuerza cuando se observa que una década después -con la reemergencia de gobiernos de derecha en la región y lo que ha sido llamado el fin del ciclo progresista-, si bien se han hecho innovaciones en las políticas sociales, estas han sido menores y se le ha dado continuidad a la lógica implantada en los años 2000. Al respeto, para el caso chileno esto se observa en el paso del Chile Solidario al Ingreso ético Familiar. Ver: Larrañaga, O., Contreras, D. y Cabezas, G. (2014) Políticas Contra la Pobreza: de Chile Solidario al Ingreso Ético Familiar. Documento de Trabajo. PNUD. Chile

${ }^{4}$ El Sistema de Protección Social Chile Solidario corresponde a una política de superación de la pobreza y la vulnerabilidad, que se constituye en ley de estado (Ley 19949) el año 2008, durante el gobierno de la presidenta Michelle Bachelet. Esta política articula servicios especializados de apoyo psicosocial, que mediante metodologías socioeducativas específicas, efectúa itinerarios de acompañamiento que facilitan la transición de familias y personas hacia otros procesos de integración social. http:// www.ips.gob.cl/servlet/internet/content/1421810829144/chile-solidarioEste sistema encuentra sus orígenes y sustenta su lógica de acción en el Programa Chile Solidario, creado el año 2002 durante el gobierno del presidente Ricardo Lagos. Este programa, cuya implementación es a la que aludo principalmente en este artículo, se trataba de un dispositivo que tenía una duración administrativa de cinco años y que durante los primeros 2 años contemplaba una intervención psicosocial directa en las familias que en términos institucionales se denominó Programa Puente. En la jerga de esta política, el Puente era "la puerta de entrada" al Chile Solidario. Por esta razón a veces se les confunde o se les asocia. En el contexto de este trabajo, utilizaré el nombre de Chile Solidario para referirme en general a la política.

${ }^{5}$ Esta investigación corresponde al trabajo realizado en el marco de la tesis de la autora: "Reconfiguration de l'Etats social dans le Chili néolibéral. Ethnographie des politiquesd'assistance”, mediante la cual obtuvo el año 2015 el grado de Doctora en Sociología por l'EHES-Paris.

${ }^{6}$ Al respecto se sugiereverCarneiro, P. and E. Galasso (2007) Lessons from the Evaluation of Chile Solidario. Washington, DC: World Bank.

7 Plataforma de Investigación “Normalidad, Diferencia y Educación”. Proyecto (SOC1103) financiado por el Programa Anillos en Ciencias Sociales y Humanidades de CONICYT.

${ }^{8}$ Programa del Ministerio de Educación de Chile, d 
${ }^{9}$ Ley $\mathrm{N}^{\circ} 20.248$ que entrega recursos a los establecimientos educaciones para trabajar en temas de equidad y calidad. Esta asignación se entrega en función del número de estudiantes ha sido identificado como prioritario. https://www.ayudamineduc.cl/ficha/ antecedentes-generales-sep-10

${ }^{10}$ Con respecto por ejemplo a las políticas de asistencia vinculadas al Chile Solidario, se observa en la evaluación realizada por el Banco Mundial (Carneiro, Galasso et Ginja, 2009), que el impacto del programa en términos de disminución delas líneas de pobreza nacional, son del orden del 0,1 punto. Ahora bien, ocurre que tales conclusiones no opacan, ni en tal informe, ni en términos del debate público el carácter de éxito de la política, debido a que muestra que el modelo de gestión que lo soporta resulta ser eficiente en términos de la evaluación de indicadores de gestión. 


\section{Bibliografía}

Ahmed, S. (2004a). The cultural politics of emotion. New York, USA: Routledge.

Ahmed, S. (2004b). AffectiveEconomies. Social Text, 22(2), 117-139. Recuperado de http://muse.jhu.edu/journals/soc/summary/v022/ 22.2ahmed.html

Astier, I. (2007). Les nouvellesrègles du social. Paris, Francia: PUF.

Bascuñán, C., Correa, G., Maldonado, J., \&Sánchez, V. (2009). Más acá de los sueños, más allá de lo posible. La concertación en Chile. Vol. I. Santiago, Chile: LOM

Bessin, M. (2014). Présences sociales: une approchephénoménologique des temporalitéssexuées du care. Temporalités, 20(2). Doi : 10.4000/ temporalites. 2944

Bourdelais, P. y Fassin, D. (2005). Les constructions de l'intolérable. Paris. Francia: La Découverte.

Brown, W. (2006). American Nightmare: Neoliberalism, Neoconservatism, and De-Democratization. PoliticalTheory, 34(6), 690-714.

Brugère, F. (2008). Le Sexe de la sollicitude. Paris, Francia: Seuil.

Castel, R. (1995). Les métamorphoses de la questionsociale. Une chronique du salariat. Paris. Francia: Fayard.

Cecchini, S. y Madariaga, A. (2011) Programas de Transferencias Condicionadas. Balance de la experiencia reciente en América Latina y el Caribe. Santiago, Chile: CEPAL.

Cefaï, D., \&Gardella, E. (2011). L’Urgencesociale en action: Eethnographie du Samusocial de Paris. Paris, Francia: La Découverte.

Chauvière, M. (2007). Trop de gestiontue le social. Essai sur une discrètechalandisation. Paris, Francia: La Découverte.

Dabène, O. (2012). La Gauche en Amérique latine, 1998-2012. Paris, Francia: Presses de Sciences-Po.

Destremau, B. y Geroges, I. (2017) Le «care», facemorale du capitalisme. Assistance et police des familles en Amérique latine. Bruselas, Bélgica: Peter Lang. 
Dorlin, Elsa, 2005, Darkcare. De la servitude à la sollicitude. En Paperman P. y Laugier S., Le souci des autres. Ethique et politique du care (pp. 87-97). Paris, Francia :Raisonspratiques, EHESS.

Duggan, L. (2003). Twilight of Equality? Neoliberalism, Cultural Politics, and the Attack on Democracy. Boston: Beacon Press.

Fassin, D. (2011). Humanitarian reason: A moral history of the present. Berkeley, USA: University of California Press.

Fassin, D., Mazouz, S., Makaremi, C., Kobelinsky, C., Fischer, N., Fernandez, F., Eideliman, J. S., Coutant, I., Bouagga, Y., y Roux, S. (2013). Juger, réprimer, accompagner. Essai sur la morale de l'État. Paris, Francia: Éditions du Seuil.

Foucault, M. (2004). Sécurité, Territoire et Population. CoursauCollège de France 1977 - 1978. Paris, Francia: EHESS-Seuil/Gallimard

Gilligan, C. (1982). In a DifferentVoice, Harvard UniversityPress, p. 19.

Carneiro, P., Galasso, E., \&Ginja, R. (2009). The Impact of Providing PsychoSocial Support to Indigent Families and Increasing their Access to Social Services: Evaluating Chile Solidario.

Han, C. (2012). Life in Debt. Times of care and Violence in Neoliberal Chile. Berkeley, USA: University of California Press.

Illanes, M. A. (2006). Cuerpo y sangre de la política. La construcción histórica de las Visitadoras Sociales (1887-1940). Santiago, Chile: LOM.

Infante, M., Matus, C., Paulsen, A., Salazar, A. y Vizcarra, R. (2012).Narrando la vulnerabilidad escolar: Performatividad, espacio yterritorio. Literatura y Lingüística, 27, 279 - 306

Luna, J. P., \& Filgueira, F. (2009). The Left Turns as Multiple Paradigmatic Crises. Third World Quarterly, 30(2), 371-395. Recuperado de http:/ /www.jstor.org/stable/40388121

Marché-Paillé, A. (2010). Le dégoûtdans le travail d’assistance auxsoinspersonnels, s'endéfendremaispastrop: Sale boulot, boulot sale.Travailler, 24(2), 35-54. Doi : 10.3917/trav.024.0035.

Memmi, D., Raveneau, G., \&Taïeb, E. (2011). Introduction. La fabrication du dégoût. EthnologieFrançaise, 41(1), 5-16. Doi: 10.3917/ ethn.111.0005

Molinier, P. (2010). Au-delà de la féminité et du maternel, le travail du care. ChampPsy, 58(2), 161-174. Doi : 10.3817/cpsy.058.0161 
Molinier P. (2013). Le travail du care. Paris, France: La Dispute.

Molyneux, M. (2007), Change and Continuity in Social Protection in Latin America - Mothers at the Service of the State? Geneva: United NationsResearch Institutefor Social Development (UNRISD)

Muehlebach, A. (2012). The moral neoliberal: Welfare and citizenship in Italy. Chicago, USA: University of Chicago Press.

Nicole-Drancourt, C. y Jany-Catrice, F. (2008). Le statut du caredans les sociétéscapitalistes. Introduction. RevueFrançaise de SocioÉconomie, 2(2), 7-11. Recuperado de http://www.cairn.info/ article.php?ID_REVUE=RFSE\&ID_NUMPUBLIE=RFSE_002\&ID_ ARTICLE=RFSE_002_0007

Paperman, P. et Laugier, S. (2005), Le souci des autres. Ethique et politique du care.Paris, Francia: EHESS.

Peña, M. (2013). Análisis crítico de discurso del Decreto 170 deSubvención Diferenciada para Necesidades Educativas Especiales: El diagnóstico como herramienta de gestión. Psicoperspectivas, 12(2),

Procacci, G. (1993). Gouverner la Misère. La questionsociale en France 1789 - 1848. Paris, Francia: Seuil.

Puar, J. K. (2007). Terrorist Assemblages: Homonationalism in Queer Times. Durham: DukeUniversityPress.

Rojas, C. (2010) Gobernar la extrema pobreza: un análisis del dispositivo de intervención Chile solidario-Puente”. En: Vanessa Lemm (edit.) Michel Foucault: Biopolítica y Neoliberalismo Editorial de la Universidad Diego Portales.

Rojas, C. (2014). Sexuación y Subjetivación en las prácticas de asistencia en Chile.Revista Cadernos de Pesquisa - Brasil. V. 44, n. 152 abr/jun 2014. Doi : doi.org/10.1590/198053142870

Rojas Lasch, C. (2015), Reconfiguration de l'Etats social dans le Chili néolibéral. Ethnographie des politiquesd'assistance, (Tesis de doctorado en sociología). Iris / EHESS, Paris, Francia.

Rose, N. (1996)The Death of the Social? Refiguring the Territory of Government, Economy and Society, 5 (3), 1996, 327-356. Doi :doi.org/10.1080/03085149600000018

Serrano, C. (1992). Estado, Mujer y Política Social en Chile. En: Raczynski, D. y Serrano, C. (edit.) Políticas sociales, mujeres y gobierno local. Santiago, Chile: CIEPLAN. 
Spire, A. (2008). Accueilliroureconduire. Enquête sur les guichets de l'immigration. Paris, Francia: Raisonsd'agir.

Tronto, J. (2009). Un monde vulnérable. Pour une politique du care. Paris, Francia: La Découverte.

Stoessel, S. (2014) « Giro a la izquierda en la América Latina del siglo XXI. », Polis, 39 | 2014, http://journals.openedition.org/polis/10453

Vargas Hernández, J. (2007). Liberalismo, Neoliberalismo, Postneoliberalismo. Revista Mad. Revista del Magíster en Análisis Sistémico Aplicado a la Sociedad, (17), 66-89.

Valencia-Lomelí, E. (2008). Las Transferencias Monetarias Condicionadas como Politica Social en America Latina. Un Balance: Aportes, Limites y Debates. AnnualReview of Sociology, 34(1), 499-524.

Recibido: 21.01 .18

Aceptado: 12.04 .18 